\title{
Managed healthcare: Treatment protocols and fiduciary duties of funders
}

\author{
D Masege, ${ }^{1}$ MB BCh, DCH (SA) FCS (SA) ORL; A Dhai, ${ }^{2}$ PhD, MB ChB, FCOG, LLM, PGDip Int Res Ethics \\ ${ }^{1}$ Department of Otorhinolaryngology/Head and Neck Surgery, Chris Hani Baragwanath Academic Hospital and University of the Witwatersrand, \\ final-year student MSc (Bioethics and Health Law), University of the Witwatersrand, Johannesburg, South Africa \\ ${ }^{2}$ School of Clinical Medicine, Faculty of Health Sciences, University of the Witwatersrand, Johannesburg, South Africa
}

Corresponding author: D Masege (dipuo.masege@wits.ac.za)

\begin{abstract}
Managed healthcare has become the cornerstone of health service delivery in the private sector in South Africa. As a result, managed care organisations and medical aid schemes have had to draw up recommended treatment protocols in accordance with the rules and regulations of the Council for Medical Schemes. The protocols are somewhat rigid, do not always consider each case on its own merit and do not always benefit the members of the respective schemes. The purpose of the protocols is to determine which treatment options constitute essential medical care and cost-effective treatment, and which do not. This article examines the fiduciary duties of the medical aids, and the existing relationship between the managed healthcare company and the members in a trustee-beneficiary duty of loyalty.
\end{abstract}

S Afr J Bioethics Law 2020;13(2):129-132. https://doi.org/10.7196/SAJBL.2020.v13i2.731

Managed healthcare has become the cornerstone of health service delivery in the private sector in South Africa (SA). As a result, managed care organisations and medical aid schemes have had to draw up recommended treatment protocols in accordance with the rules and regulations of the Council for Medical Schemes (CMS). CMS is a statutory body established under the Medical Schemes Act No. 131 of 1998. ${ }^{[1]}$ Most protocols are rigid, do not always consider each case on its own merit and do not always benefit the members of the respective schemes. The purpose of the protocols is to determine which treatment options constitute essential medical care and which do not. All role players in the healthcare industry should distribute healthcare in the context of their fiduciary duties to their members and patients. The principle of fiduciary duty is well established in the doctor-patient relationship, a relationship of trust and confidence. ${ }^{[2]}$

Managed healthcare is defined in regulation 15 of the Medical Schemes $\operatorname{Act}^{[3]}$ as:

'clinical and financial risk assessment and management of healthcare, with a view to facilitating appropriateness and costeffectiveness of relevant health services within the constraints of what is affordable, through the use of rules-based and clinical management-based programmes. ${ }^{[3]}$

The intention of managed healthcare is to curb the ever-increasing cost of private healthcare and through the use of rules and protocols set by managed care companies and the medical aids, to share the health funding pie equitably. ${ }^{[3]}$ The selection or rejection of health services are to be based on sound clinical judgement from all the stakeholders, which include clinicians, case managers at the managed care organisation, the hospital and, lastly, the medical scheme itself, hereafter called the funders. In its original form, managed healthcare was intended to save costs without compromising quality of care. ${ }^{[4]}$ However, because of the rigid 'cookbook' approach, which follows particular 'recipes', the protocols used by medical aid schemes are somewhat rigid, and are not allowed to be tailored for a specific case should the need arise.

This article starts with a case report on a rigid approach by a medical aid, which, if followed, would have resulted in serious morbidity, if not mortality. The subsequent analysis makes the argument that it is time for these protocols to be reviewed, as medical aids are declining essential services in breach of their fiduciary duties to their members, at times, to the detriment of the patient and their dependents. It must be recognised that the one-size fiduciary law does not apply to all fiduciary relationships.

\section{Case report}

An 18-month-old child was referred to a surgeon for an opinion for a swelling on the side of the left jaw. The child had been treated by a general practitioner (GP) with appropriate medication for 5 days and was not getting better. The GP decided to refer the child for a specialist opinion. After consultation with the mother and child, the specialist made a diagnosis of a left parotid gland abscess (Fig. 1).

In view of the poor response to oral medication and the fever that was not subsiding, the specialist decided to admit the child for intravenous antibiotics and for possible incision and drainage of the abscess. Following the procedure required by medical aids, the next step was to obtain authorisation to admit the child. After the clinical case was presented to the case manager at the medical aid and the treatment plan outlined, the response from the medical aid was to decline the admission. The message was that 'there is no need for admission as the child could take the medication orally at home.' Despite a telephonic motivation, the decision stood. Some time later, authorisation was given to admit the child for only one night, and for the case managers of the admitting hospital to 'update' the 
case the following day. The child continued to have temperature spikes on intravenous medication, and after 48 hours of antibiotics and despite aspiration of the abscess, there was a need to take the patient to theatre (Fig. 2). Incision and drainage of the abscess was done, and the child was well enough to be discharged the following day, after the procedure.

\section{Discussion}

Managed healthcare is inevitable due to spiraling healthcare costs and advances in medical technology that further compound costs. There are several healthcare funding methods that have been

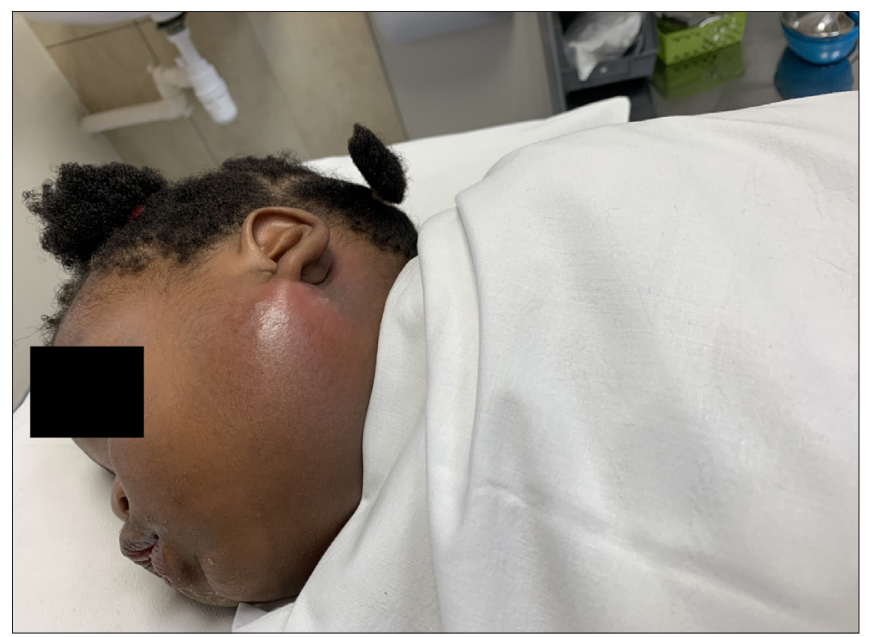

Fig. 1. Parotid abscess day 1 post admission (permission obtained from the mother to use the child's picture for purposes of scholarly activities).

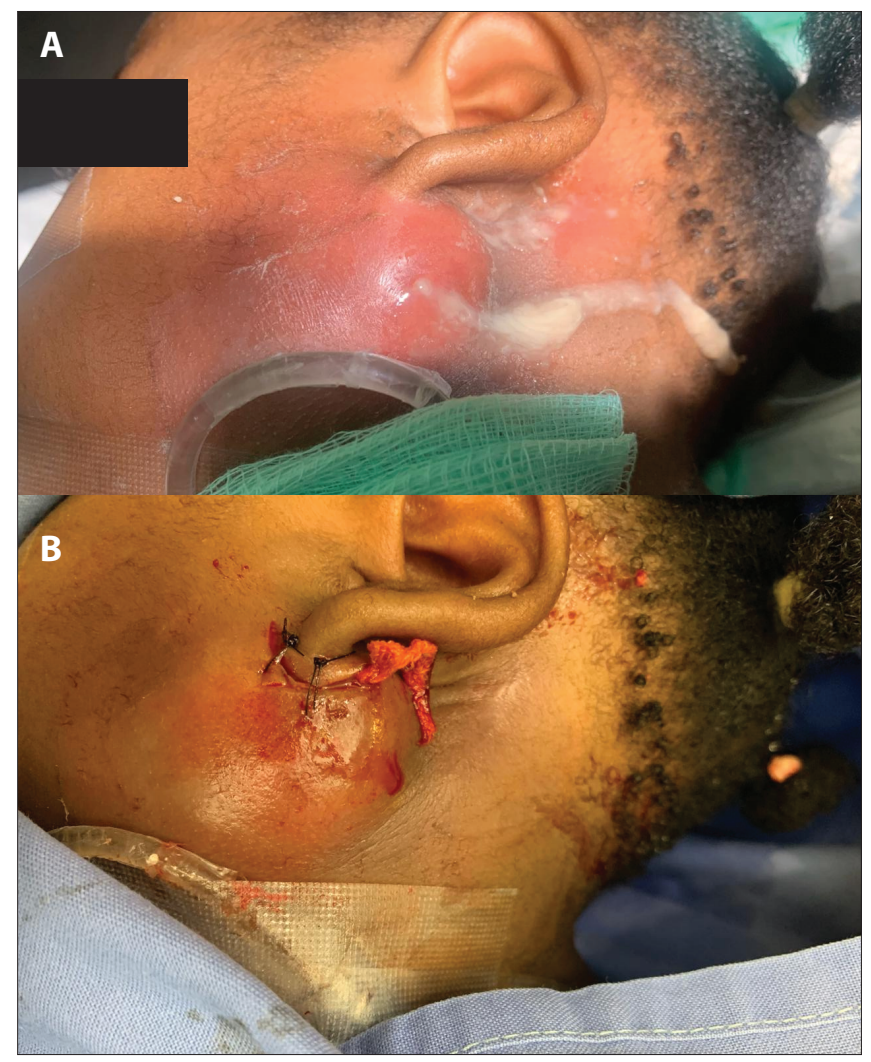

Fig. 2. Intra-operative. A. Before incision and drainage. B. After incision and drainage. tested in addressing the healthcare needs of society, including fee-for-service, capitation and health maintenance organisation. There is no single method that is foolproof and that is not without problems. Key to the managed care approach is the prospective or current review of treatment provided to individual patients, with the power to deny payment for care deemed by the insurer to be unnecessary or not cost-effective. The managed care organisation has to fulfil the criteria set out by the Medical Schemes Act of 1998, in particular section $15 \mathrm{D}(\mathrm{b})$, which reads as follows: $:^{[3]}$

'The managed healthcare programmes use documented clinical review criteria that are based upon evidence-based medicine, taking into account considerations of cost-effectiveness and affordability, and are evaluated periodically to ensure relevance for funding decisions.'

Clinical and financial risk assessment in this case report clearly reveals that the medical aid found one aspect (cost saving) to be superior to the other (clinical presentation). This case illustrates the potential shortcomings of treatment protocols and the cookbook approach. In addition, the treating physician is faced with difficult moral problems and is put at risk of litigation should the treatment not be appropriate and in keeping with sound clinical acumen. ${ }^{[5]}$

In the fiduciary medicine model, ${ }^{[2]}$ there is no one-size-fiduciarylaw-fits-all fiduciary relationship. Fiduciary law requires an expert to exercise his or her knowledge, judgement and selfless discretion in protecting a weaker party who is dependent on the expert, without having sufficient knowledge to effectively argue with the expert. In this instance, patients do not have the expertise to argue against the medical aid experts when these experts refuse to pay for their care, and are thus vulnerable to decisions that may not at all times be in their best interests. It is argued that the medical aid abandons its fiduciary duty to its member when it declines clinically indicated beneficial care. Furthermore, this case involved a child. Ethically, and in the law, with this being affirmed inter alia in the SA Constitution, ${ }^{[6]}$ the child's best interests are of paramount importance in any activity involving a child. This is based, presumably, on children being highly vulnerable and requiring special protections. By the medical aid initially declining treatment, its action could also be perceived as being unconstitutional.

Biomedical principles as suggested by Beauchamp and Childress ${ }^{[7]}$ are useful in the analysis of ethical dilemmas, and are: respect for autonomy (the obligation to respect the decision-making capacities of autonomous persons); non-maleficence (the obligation to avoid causing harm); beneficence (obligations to provide benefits and to balance benefits against risks); and justice (obligations of fairness in the distribution of benefits and risks). ${ }^{[7]}$ In Beauchamp and Childress' assertion on justice, there is no single principle that can be used to address all problems of distributive justice. The funders use the utilitarian justice principle to defend allocation of resources where the benefits to patients and society as a whole, and not just to a single individual, are maximised. These are prima facie principles, and no one principle is ranked as more important than another. Where principles conflict, the physician will need to rely on those that are most compelling to guide ethical reasoning. In this case, non-maleficence and beneficence would be the most persuasive for the physician. 
Autonomy is a core value in healthcare. It applies to both patients and physicians. More and more, doctors' autonomy is being usurped by external factors, including third-party funders, and as a consequence, patient care is interfered with. Physicians are often placed in uncomfortable dual-loyalty conflicts that result in them being morally distressed. The doctor, an autonomous professional, is entitled, because of the training received and the trust that society has placed in him or her, to act in the best interest of the patient. ${ }^{[8]}$ Society, too, is entitled to care that is in line with the principles of non-maleficence and beneficence. As illustrated in this case report, the doctor used his clinical expertise and applied his mind in coming to the conclusion that the child needed admission, intravenous antibiotics and possible drainage of the abscess. His autonomy was impeded by the case manager at the managed care company, who in all probability may have lacked the medical training that the surgeon had undergone. ${ }^{[9]}$ In effect, the case manager made the decision by looking at a protocol on a computer screen without taking into consideration the specifics of the individual case.

Despite this case being a prescribed minimum benefit (PMB) condition, the funder initially refused to accept the case. It is a reasonable expectation for funders to act in good faith and in fairness and loyalty to their enrolled client when considering cases like this. When members join a scheme, they are usually under the impression and assurance that in the event of a medical condition, they will be covered by their scheme. However, as seen by the case described, this is not necessarily the case. PMB conditions would align with Beauchamp and Childress' ${ }^{\prime[]}$ distributive justice principle, as these conditions are prescribed as the basic level of treatment given to scheme members in order to protect their rights to basic healthcare where conflict with justice may arise. These PMBs are enforced by the Medical Schemes Act of 1998, annexure $A_{r}^{[1]}$ and they may not be refused. Furthermore, PMBs need to be considered as a response to section 27 of the Constitutional right to basic healthcare in SA.

\section{Doctors as fiduciary agents}

The social contract theory advances that the medical profession lends itself to society as custodians of a body of knowledge on health matters. In turn, the society acknowledges this, and allows doctors to have a monopoly over this body of knowledge. Doctors have to use this knowledge to benefit society. This is what confers on them the status of fiduciary agents - they have something that is meant to be used to benefit those who are vulnerable. ${ }^{[2]}$ They possess this body of skills and knowledge to bring health to society, and where possible, prevent early death. Doctors are duty bound to always act in the best interest of the patient. ${ }^{[4,7,8]}$

In Wickline v State of California, the courts found in favour of the patient and against the doctor because the doctor had failed in his fiduciary duties to the patient. ${ }^{[4]}$ The doctor had accepted prima facie instruction from the medical aid to discharge a patient without motivating for a longer hospital stay, despite the doctor realising the need for this. The patient lost her leg in the process. The fiduciary duty of the doctor to always advocate for and be loyal to the best interests of the patient was put to the test. Doctors have obligations to always try to persuade managed care to pay for the services they deem necessary and beneficial to their patients.
The Hippocratic Oath compels doctors to be loyal to the patient. Inherent in this is that financial incentives should not cloud their judgement and ethical behavior. Moore v Regents of Univ. of Calif is a good example of case law that provides for and clarifies the doctor's loyalty to the patient. The law ruled in favour of the patient because the doctor did not obtain permission to use the patient's spleen cells for financial gain. The patient's reliance on the doctor was based on trust. ${ }^{[10]}$

That doctors are fiduciary agents was also underscored in the case of Jansen van Vuuren and Another NNO v Kruger, which hinged on respect for confidentiality. The appeals division judge ruled in favour of the patient, and against the doctor, because he had breached patient confidentiality in disclosing the patient's HIV status to two colleagues on the golf course without the patient's informed consent. ${ }^{[12]}$

The attributes of dependency, trust and information asymmetry are all indicative of a fiduciary duty on the part of the doctor, and as has been illustrated, the courts have ruled that doctors are fiduciary agents. ${ }^{[2,4]}$ Patients expect their doctors to act in their best interest, not because of a contract between them, but due to the nature of the relationship ${ }^{[2]}$ Doctors are called upon to draw on the core ethical values when dealing with patients, and essential in these are trust and integrity. Trust is the basis on which patients consult doctors for healthcare. They entrust their whole being and innermost secrets to the doctor. ${ }^{[8]}$ Unfortunately, managed care erodes this trust, and undermines doctors' roles as fiduciary agents.

It is interesting to note that the courts have held that healthcare facilities are not fiduciary agents. In Moore v Regents of the University of California, 793 P.2d 479 (Cal. 1990), the courts held that the facility was not a fiduciary, and that the healthcare facility was only a fiduciary in so far as concerned disclosure of medical errors to patients. ${ }^{[10]}$ In Sherwood v Dansbury, the Supreme Court of Connecticut ruled that informed consent rested with the treating doctor, and the facility did not owe any fiduciary duty to the patient. In addition, in Moore v Regents of the University of California, 793 P.2d 479 (Cal. 1990), the courts ruled that none of the other entities, including the healthcare facility, owed any fiduciary duty to the patient, save for the doctor. ${ }^{[4]}$ The role of hospitals is merely to safeguard the safety of the patient for the doctor, and the doctor has the ultimate responsibility.

\section{Healthcare funders as fiduciary agents}

Because all trusts are fiduciary relationships, ${ }^{[2]}$ and funders are trustees who hold the patients' monies in trust, they therefore have the fiduciary duties of trustees. In trust law, a trust is a relationship between parties in relation to property. In that trust, an individual transfers legal title of the property into the hands of a trustee, while the person still retains ownership of the same property. In this instance, the trustee is the legal owner of the property on behalf of the individual. The trustee is given a set of duties to deal with the property for the benefit of the beneficiary, with clear remedial actions that will be taken if the trustee misuses the property and does not fulfil those duties. Trustees owe a duty of undivided loyalty to the beneficiaries, in this instance medical aid members. The duty of loyalty is purely on the basis of a relationship between the two, and not necessarily because of a contract. Thus the trustee needs to act in good faith on behalf of the beneficiary. It is the same with medical aid members. They entrust their monthly premiums to the trustees to 
manage the funds on their behalf, with clear duties entrusted to the trustees by the board. The trustee must act solely in the best interest of the beneficiary, and not on behalf of a third party, in this instance, shareholders or managers who are going to share in the profits if healthcare is declined and the funds are diverted.

As a result, the insurer or funder does have a fiduciary duty. They have an ongoing contract with the patient, with the promise that they will safeguard premiums deposited into their account, they will invest the funds and will take full responsibility for how this money will be spent. Health insurers do more than just pay medical bills. They administer the members' funds prudently, as required by CMS rules. They authorise care, decline care and choose which facility is accredited by a particular scheme. They enter into service agreements with doctors and healthcare facilities on behalf of their members. All of these constitute fiduciary duties. ${ }^{[13]}$

They also take full fiduciary responsibility by undertaking, on behalf of the patient, to determine, prior to treatment, which procedures are deemed necessary and which are not medically necessary and not cost-effective. ${ }^{[11,13]}$ In the USA, it is clearly stated that insurers are indeed fiduciary agents: according to the Employee Retirement Income Security Act of 1974, all insurers are fiduciary agents. ${ }^{[13]}$ In holding the assets, trustees of medical aids are required to be prudent in managing trust assets, and as such are seen as fiduciary agents. ${ }^{[14,15]}$

In the SA context, there is guidance from both the Medical Schemes $\mathrm{Act}^{[3]}$ and the CMS, a statutory body created by the Act. In support of the funder being a fiduciary agent, section 35 of the Medical Schemes Act provides for the sound financial management of the medical aid and the prudent use (my emphasis) of funds entrusted to the scheme by the members. Section 35(13) states that 'if a medical scheme fails to comply with any provision of this section, every officer of the medical scheme who is a party to the failure shall be guilty of an offence. ${ }^{\cdot[1]}$

\section{Conclusion}

In terms of both ethics and law, it is clear that the doctors have fiduciary duties to their patients. Funders, too, have fiduciary duties because they hold their clients monies in trust for healthcare needs. Funders are also mandated by CMS and the Medical Schemes Act to act on behalf of their members in a cost-effective manner without compromising quality of care. Trustees of medical aid schemes owe loyalty to their beneficiaries inherent in the trustortrustee relationship. The funder, in dealing with this case, was out of line with their fiduciary duties by initially refusing care where it was desperately needed by a vulnerable member of society, as espoused by the Constitution of the Republic ${ }^{[6]}$ and the Children's Act. ${ }^{[16]}$ These rights are only limited conditional to the limitations being reasonable and justifiable as affirmed in section 36 of the Constitution. However, the child's rights to dignity and life are non-derogable, and that refusal of treatment would also amount to a Constitutional infringement.

Acknowledgements. The authors would like to acknowledge the patient and the mother for allowing us to use this as a case presentation, and for the pictures provided. We would also like to thank Prof. Ames Dhai for her tireless contribution to the manuscript and for always finding time even when she was so inundated with work.

Author contributions. DM conceptualised the idea, did the original research and wrote the original draft. Ames Dhai equally contributed by further research, formal analysis, review and editing of the manuscript.

Funding. None.

Conflicts of interest. None.

1. Medical Schemes Act No 131 of 1998. https://www.medicalschemes.com/files/ Acts\%20and\%20Regulations/MSACT19July2004.pdf (accessed 27 April 2020).

2. Matthew, DB. Implementing American health care reform: The fiduciary imperative. 59 Buff L Rev 2011;715:59. http://scholar.law.colorado.edu/articles/169 (accessed 27 March 2020).

3. Medical Schemes Act No. 131 of 1998. Regulations in terms of Medical Schemes Act No. 131 of 1998. https://discover.sabinet.co.za/webx/access/netlaw/131_1998 medical_schemes_act_131_of_1998.htm (accessed 27 April 2020).

4. Mehlman, MJ. Why physicians are fiduciaries for their patients. Indiana Health Law Rev 2015;12(1):1-64. https://doi.org/10.18060/18959

5. Rachels J, Rachels S. The Elements of Moral Philosophy. 8th ed. New York: McGraw-Hill, 2015:113.

6. The Constitution of the Republic of South Africa, 1996.

7. Beauchamp TL, Childress J. Principles of Biomedical Ethics. New York: Oxford University Press, 1st ed. 1979; 5th ed. 2001.

8. World Medical Association. WMA Medical Ethics Manual, 3rd ed. Ferney-Voltaire: WMA, 2015:34-63.

9. Mahlo S, Muller M. Problems experienced by role players within the managed healthcare context in Gauteng. Curationis 2000;23(2):37-41. https://doi.org/10.4102/ curationis.v23i2.641

10. Criddle, EJ, Miller PB, Sitkoff RH, Hall MA. Fiduciary Principles in Health Care. The Oxford Handbook of Fiduciary Law. Oxford: Oxford University Press, 2019. https:// www.oxfordhandbooks.com/view/10.1093/oxfordhb/9780190634100.001.0001/ oxfordhb-9780190634100-e-15 (accessed 27 April 2020).

11. Appelbaum, PS. Legal liability and managed care. American Psychologist 1993;48(3):251-257.

12. Dancaster TJ, Dancaster LA. Confidentiality concerning HIV/AIDS status - the implications of the Appeal Court decision. S Afr Med J 1995;85(3):141-144.

13. Rush Prudential HMO. 2002., Inc. v Moran, 536 U.S. 355. Cornell Law School.

14. CriddleEJ, Miller PB, SitkoffRH, Goldberg JCP.The Fiduciary Duty of Care. The Oxford Handbook of Fiduciary Law. Oxford: Oxford University Press, 2019. https://www. oxfordhandbooks.com/view/10.1093/oxfordhb/9780190634100.001.0001/ oxfordhb-9780190634100-e-21 (accessed 27 April 2020).

15. Shea v Esensten, 107 F.3d 625, 629.

16. South Africa. Children's Act No. 38 of 2005. https://www.gov.za/documents/ childrens-act (accessed 25 May 2020)

Accepted 12 October 2020 